\title{
Resumen
}

La muerte cerebral o muerte encefálica es un concepto reciente en medicina que ha despertado una intensa controversia ética, cultural y biomédica que interesa no sólo a los neurólogos, trasplantólogos y jueces. Su diagnóstico es en esencia clínico, no obstante, significa un gran reto para el médico observador. Los métodos paraclínicos pueden ayudar, acortando el tiempo de observación y son necesarios en casos de intoxicación por neurotóxicos, hipotermia o en recién nacidos.

Palabras claves: muerte cerebral, tanatología, coma, actividad cortical, gamagrafía de perfusión cerebral

\section{Reseña histórica}

Durante más de treinta siglos de civilización sólo se conoció el concepto de muerte en general, pero en el siglo XX con el invento del respirador la tanatología dio un sorpresivo giro.

Es un concepto relativamente nuevo en medicina, solo a partir de la mitad del siglo XX fue introducido, para referirse a un grupo de pacientes en coma muy profundo que mantenían signos vitales en forma artificial sin presentar reflejos; en 1968 en la escuela de medicina de Harvard se integró un comité compuesto por 10 médicos, un teólogo, un abogado y un historiador. La definieron como un daño total y permanente del cerebro, de carácter irreversible que incluye al tallo cerebral. En 1976 la opinión mundial se conmocionó cuando la joven Karen Ann Quinlan en New Jersey entró en coma barbitúrico y su padre solicitó a los médicos que la desconectaran del respirador en vista de que no mejoraba, a lo cual se negaron. Acudió entonces al tribunal supremo del Estado, el cual le dio la razón y se desconectó, pero la gran sorpresa fue que la paciente no solo respiró espontáneamente, sino que vivió por 9 años más. Hoy sabemos que hasta $39 \%$ de los pacientes con muerte cerebral (MC) tienen movimientos espontáneos originados en la médula espinal, uno de ellos es la extensión de los brazos (el signo de Lázaro). Su definición

\footnotetext{
Jefe del Servicio de Medicina Nuclear, Hospital de San José. Profesor Asociado Fundación Universitaria de Ciencias de la Salud. Bogotá D.C., Colombia.
}

en la práctica clínica es cada vez más necesaria en razón a la demanda siempre insatisfecha de donación de órganos, así como el creciente desarrollo de las técnicas de soporte vital y la actitud de la sociedad frente a la bioética y la muerte digna. Todo esto ha llevado a la obtención de métodos confiables de diagnóstico de MC y ya los métodos tradicionales como el electroencefalograma (EEG) pueden resultar insuficientes, en especial, en casos de coma barbitúrico (para la supresión de la actividad metabólica cerebral, por ejemplo); de otro lado, los métodos clínicos a la cabecera del paciente tienen una certeza diagnóstica en el $83 \%$ de los casos y su definición tiene un impacto clínico, ético, económico y legal.

Hoy se sabe que el silencio eléctrico no es una prueba idónea de MC, como tampoco es completamente cierto que el flujo sanguíneo activo sea una señal siempre inequívoca de que no la hay. Hace poco se ha propuesto el nombre de muerte encefálica en lugar de MC al definir con mayor precisión el daño del tallo además del cerebro. En Europa algunos le llaman cerebro de respirador, en Japón la MC no es aceptada por razones culturales, en Chile solo se habla de ella si va a ser donante.

El concepto de muerte ha sufrido grandes cambios a lo largo de la civilización: para la cultura griega era el cese de la actividad cardíaca, para la judaico-cristiana era el cese de la respiración, en la edad media era la separación del cuerpo del alma y se empezó a dudar de la ausencia de pulsación cardíaca y la respiración, du- 
rante el renacimiento se decía que era el justo momento en que se iniciaba la putrefacción de los tejidos. Para el siglo XVI era la aparición de livideces. Son numerosos los escritos medievales manifestando el terror de ser sepultados vivos por diagnósticos mal hechos por los familiares o vecinos del difunto. En el siglo XVIII se iniciaron las maniobras de reanimación y con ellas toda suerte de adminículos para ayudar al diagnóstico: espejos, plumas, velas, burbujas por inmersión en agua, trompetas; se enredó de tal manera el diagnóstico y el temor a errar que se le empezó a encomendar esta función al médico. En este escenario hizo su debut el estetoscopio de Laenec, permitiendo la auscultación cardíaca y pulmonar.

En Ciudad del Cabo se realizó el primer trasplante cardíaco en 1967 a partir de un donante con funciones vitales activas pero en muerte cerebral, con un profundo impacto bioético. A partir de allí, se unificó el concepto vigente hoy que la define como el cese irreversible de las funciones cerebrales, incluyendo las del tallo cerebral. Mallaret y Goulon sugirieron el término estado más allá del coma, Beecher, Adams y Sweet sugirieron el término muerte cerebral.

\section{Biología de la muerte cerebral}

La muerte es un proceso que no ocurre sincrónicamente en todos los tejidos. Así por ejemplo, después de la muerte algunos tejidos como el epitelio intestinal es de los primeros en iniciar su descomposición, en tanto que otros como el cabello y las uñas siguen creciendo activamente por algunos días más.

La MC es un estado de coma profundo con daño cerebral extendido e irreversible, en el cual las funciones cardiopulmonares son mantenidas de manera artificial. El requisito básico es la ausencia de actividad cortical (EEG plano) y la ausencia de reflejos del tallo, entre los cuales la apnea es el más prominente, seguidos por fotomotor o pupilar, corneano, vestibular y orofaríngeo. Existen tres guías de criterios clínicos: Harvard, Minnesota y Schwab.

La más difundida en el mundo corresponde a los Criterios de Harvard: ausencia de reflejos con temperatura corporal mayor de $32^{\circ} \mathrm{C}$, apnea mayor de tres minutos, falta de movimientos espontáneos, ausencia de fármacos depresores del SNC, EEG isoeléctrico y repetición de todas estas pruebas 24 horas después, con resultados iguales. Es necesario recordar que la Asociación Americana de Neurología es muy exigente con la prueba de apnea en adultos y niños y deben cumplirse al menos doce requisitos para que este examen, de máxima importancia diagnóstica, sea válido.

En todos los casos habrá buena oxigenación y ausencia de hipotensión, hipercarbia o hipotermia. Unas pruebas tan simples como antiguas son la falta de respuesta cronotrópica a la atropina y el descenso de la temperatura local en el cuero cabelludo entre 5 y $8^{\circ} \mathrm{C}$.

Estos criterios han originado controversias pero sin lugar a dudas lo más importante es la validez de ellas en la población infantil, en especial en los recién nacidos y lactantes menores en los cuales la mecánica cerebral se comporta de manera distinta al niño mayor y aún más al adulto por cuanto el compartimiento craneano tiene mayor plasticidad, porque las suturas no están aún fusionadas; la mecánica de la hipertensión endocranea es distinta, lo cual hace necesaria una redefinición de la muerte cerebral en niños. A diferencia del adulto, la observación de estos reflejos puede extenderse hasta por 24 horas para los lactantes y 48 o más para los recién nacidos.

\section{Marco legal}

La legislación colombiana se ha ocupado del tema mediante el decreto 1172 de junio 6 de 1989 que regula además la donación de órganos y fue modificada por el decreto 1546 del año 1998. Desde el punto de vista jurídico es la ausencia de los seis reflejos del tallo y su diagnóstico es en esencia clínico y no es procedente en casos de "alteraciones tóxicas y metabólicas reversibles" y en casos de "hipotermia inducida" y forman parte del régimen jurídico del sector salud.

Pide al menos seis horas de observación clínica y la valoración de dos médicos, uno de los cuales sea especialista en ciencias neurológicas y no relacionado con el equipo de trasplante de órganos. La ley colombiana no establece diferencias entre adultos y niños. 
Estos criterios varían en los países, por ejemplo, en Estados Unidos la MC no puede ser declarada por métodos puramente clínicos en cualquier niño menor de siete días de edad. En recién nacidos entre siete días y dos semanas de edad son precisos dos exámenes clínicos y EEG al menos con 48 horas de diferencia; de dos meses a un año necesitan dos exámenes clínicos y dos EEG al menos con 24 horas de diferencia, aunque el segundo EEG puede ser reemplazado por una imagen de flujo. Para niños mayores de un año y adultos el único requisito es el examen clínico en 12 horas de observación. En otros países se exige al menos una imagen que demuestre ausencia de flujo.

\section{Diagnóstico paraclínico}

Son muchas las técnicas paraclínicas existentes para el diagnóstico de MC, siendo el EEG y los potenciales evocados los más usados por su disponibilidad e inocuidad, sin embargo, son éstos los que ofrecen mayor número de falsos positivos y negativos. Las técnicas más fiables son aquellas que se basan en el estudio del flujo sanguíneo cerebral, todas muy buenas, prevaleciendo aquella en la cual cada institución tenga más experiencia y acortando el tiempo de observación exigido legalmente para las pruebas clínicas.

La angiografía contrastada de cuatro vasos ha sido considerada como la prueba de oro, pero es una técnica de alta complejidad que requiere un neurorradiólogo, cateterización femoral e inyección en carótidas internas y arterias vertebrales. La angiografía digital en época reciente la ha simplificado. Un aspecto negativo de este recurso diagnóstico puede ser el deterioro que pueden inducir los agentes de contraste sobre órganos potenciales para donación.

\section{Métodos con radionúclidos}

Una técnica más sencilla y de buena correlación con la angiografía de cuatro vasos es la gamagrafía de perfusión cerebral que desde muchos años se ha venido realizando en nuestro país utilizando $99 \mathrm{mTc0} 4$ o 99mTcDTPA, agentes no difusibles, que en condiciones normales no atraviesan la barrera hematoencefálica, pero el hecho de poder identificar la imagen clásica de tridente (Figura 1) constituida por las dos carótidas como mango y el tridente formado por las dos cerebrales medias por fuera y las dos cerebrales anteriores unidas como una sola en el centro, son prueba de flujo sanguíneo al cerebro y unos cinco segundos más tarde la fase venosa identifica los senos sagital y transverso (Figura 2); el seno longitudinal superior no sirve por cuanto se confunde con la perfusión del cuero cabelludo dado por la carótida externa.

En la MC generalmente no se identifican los senos sagital ni transverso (Figuras 3 y 4) La principal dificultad radica en los bolos de mala calidad que no permiten ver carótidas compactas ni mucho menos las cerebrales y fácilmente se convierten en un falso positivo. Igual puede ocurrir con el trauma craneoencefálico extenso y hematomas. Tiene una gran limitación, pues no permite estudiar la fosa posterior ni el tallo, pero el principal escollo radica en que a menudo es falsa negativa en los niños menores de edad, por las razones ya comentadas. Este último argumento ha hecho que el abordaje diagnóstico en niños se haga con agentes difusibles o lipofílicos y reservemos los no difusibles con pertecnectato para los adultos.

Los agentes lipofílicos del tipo del HMPAO y la iodoanfetamina (IMP) de manera normal pasan la barrera hematoencefálica (Figura 4), tienen una alta tasa de extracción por la corteza cerebral, prolongada retención, casi no sufren metabolización y son muy estables in vivo. El etinilcisteinato (ECD) tiene un compor-

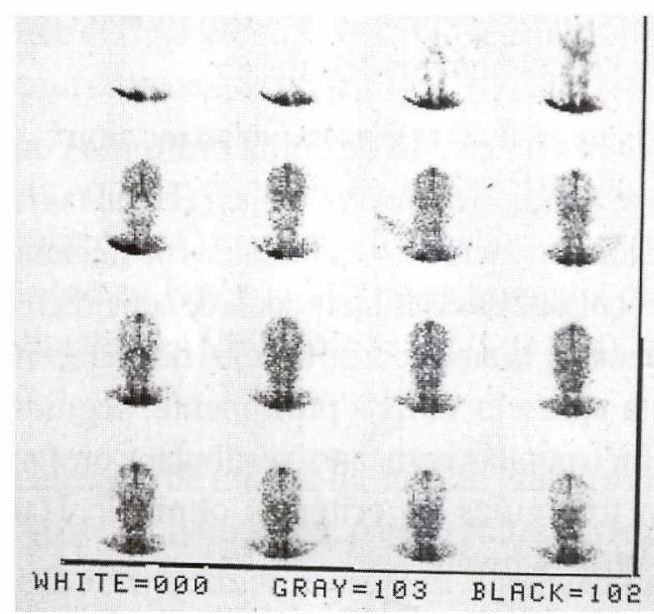

Figura I. Flujo sanguíneo normal. Fases arterial, capilar y venosa, cada imagen representa un segundo, radiofármaco $99 \mathrm{mTc0} 4$. 


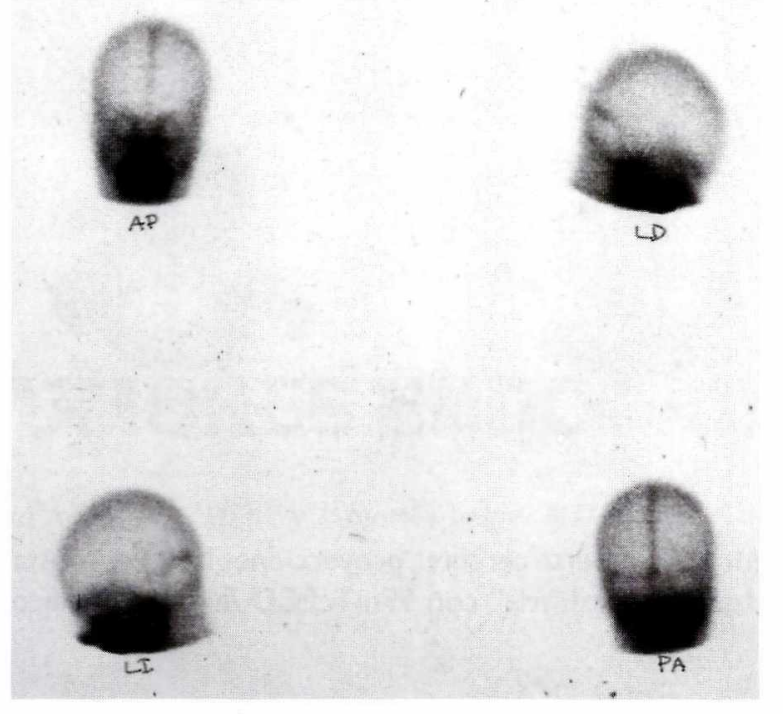

Figura 2. Imágenes estáticas normales mostrando senos venosos sagital y transversos, el $99 \mathrm{mTc04a}$ es hidrofílico y en condiciones normales no se fija a la corteza cerebral por no cruzar la barrera hematoencefálica.

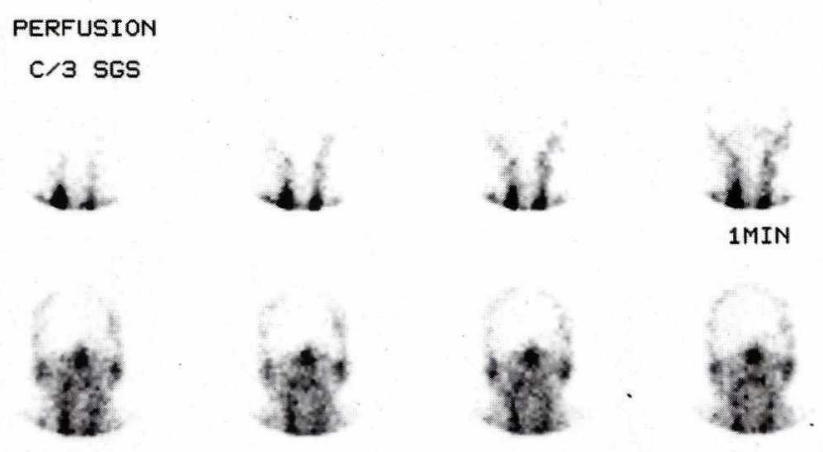

Figura 3. No hay flujo sanguíneo cerebral, no se identifican vasos cerebrales ni senos venosos, sólo existe redioactividad en cuero cabelludo. Radiofármaco $99 \mathrm{mTc} 04$.

tamiento similar al HMPAO pero sufre metabolización en la corteza cerebral, pasando a ser un compuesto no lipofílico y quedando atrapado en el sistema nervioso; tiene a su favor una estabilidad in vitro hasta de seis horas, comparado con los sólo veinte minutos del HMPAO no estabilizado. Aunque en teoría el ECD (Figura 5) serviría para el diagnóstico de MC, la verdad es que casi toda la experiencia es con el HMPAO. En la $\mathrm{MC}$, los hemisferios cerebrales y el cerebelo se observan "fríos" o vacíos. (Figuras 6A y 6B).

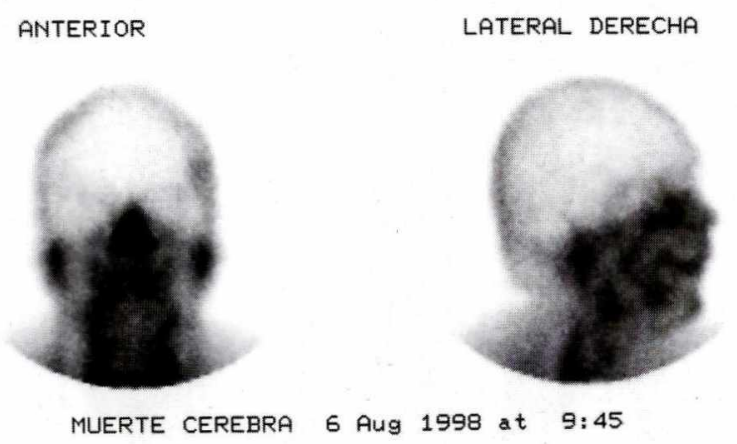

Figura 4. Muerte cerebral, imagen estática planar, no se identifican los senos venosos, radioactividad en cuero cabelludo (irrigación de la carótida externa), signo de la nariz caliente (hot nose). Radiofármaco $99 \mathrm{mTc} 04$.

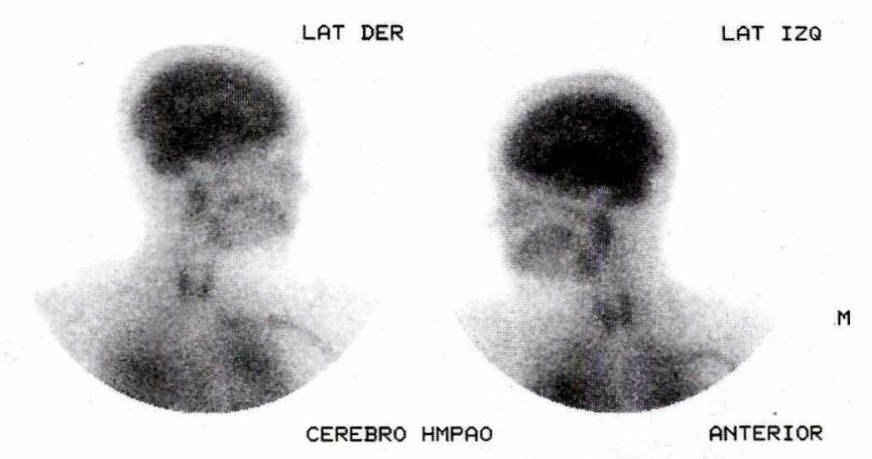

Figura 5. Estudio estático planar lateral, mostrando fijación normal del radiotrazador lipofílico $99 \mathrm{mTcHMPAO}$ en la corteza cerebral, indicando que existe flujo sanguíneo cerebral regional.

\section{Recomendaciones técnicas}

El estudio con agentes lipofílicos se hace mediante imágenes planares (no tomográficas) obteniendo proyecciones anterior y laterales reuniendo 500.000 cuentas, el procedimiento total dura entre cinco y ocho minutos. No existe razón para hacer tomografía (Spect) por cuanto no aporta mayores datos e implica al menos 25 minutos de examen en una gamacámara de un solo detector, en un paciente inestable, con ventilador y múltiples elementos de monitoreo y soporte. La dosis debe ser de $30 \mathrm{mCi}(1110 \mathrm{MBq})$ para un adulto o $5 \mathrm{mCi}$ (185 MBq) para niños, inclusive los recién nacidos para obtener una alta tasa de conteo. Es de la mayor importancia la calidad de la inyección, así como hacerla lo 


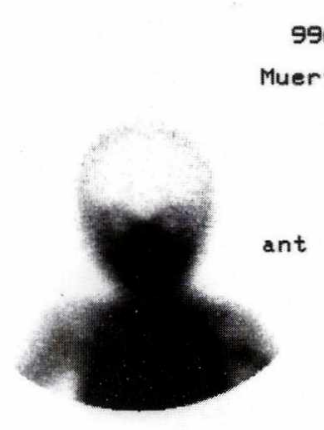

$99 \mathrm{mTC}$ ECD

Muerte Cerebral

nt

ant

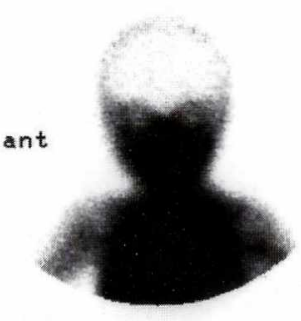

Figura 6A. Estudio planar estático, proyección anterior en niño de 7 meses, mostrando falta de fijación cortical del agente lipofílico 99mTcECD,"cerebro vacio" (empty brain), indicando muerte cerebral.

más central posible y las imágenes se pueden obtener cinco o diez minutos después.

Si en el estudio con pertecnetato era fundamental la calidad del bolo, en el uso de aminas lipofílicas es esencial el control de calidad del radiofármaco; en lo posible debe conocerse la cromatografía y debe desecharse aquel compuesto con marcaciones inferiores al $85 \%$, por cuanto se disminuye en forma progresiva la fijación cortical y es fácil obtener un falso positivo por esta causa.

\section{Otros métodos paraclínicos}

Estudios metabólicos con FDG-glucosa: se realiza con Flúor18 emisor de positrones y se basa en el principio de que en MC no existe consumo de glucosa ni fijación cortical. La espectroscopia por resonancia magnética nuclear: es un método idóneo de flujo sanguíneo; el Doppler transcraneal es un excelente método no invasivo que en algunos casos ha mostrado superioridad al HMPAO. Los potenciales evocados auditivos y potenciales somatosensoriales revelan ausencia de ondas N20-P22 al estimular el nervio mediano.

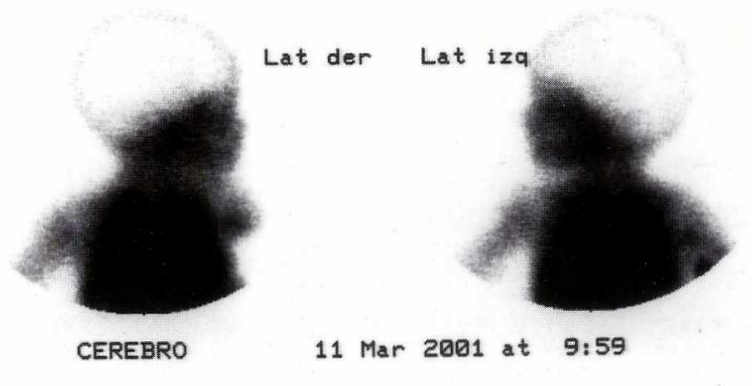

Figura 6B. Muerte cerebral, proyecciones laterales mostando corteza cerebral "fría" con 99mTcECD (agente lipofílico).

\section{Lecturas recomendadas}

Adams R, VM Principles of Neurology. McGraw-Hill; 1998. pp 305-306.

Ball, WS, Jr Am J Neuroradiol 1998 Apr; 19(4): 796.

Carreras, JL, Sopena R, Llamas, JM. Aplicaciones clínicas de la Spect Cerebral. Barcelona: Masson; 1994. pp. 57-63.

Centanaro; G. Muerte cerebra.1 En: www.geocities.com/gcenta/ muerceb

Toro J, Coma. En: Toro, J, Yepes M, Palacios E. Neurología. Bogotá: McGraw Hill; 2001. pp.91-104.

\section{Agradecimientos}

Por su revisión, comentarios y sugerencias a los doctores: Manuel Roberto Palacios y Juan Antonio Becerra neurocirujanos Hospital de San José, Fundación Universitaria de Ciencias de la Salud; a la doctora Gladys León, abogada asesora del Tribunal de Ética Médica de Cundinamarca y al doctor Darío Cadena por la corrección editorial. 